\title{
Codification method and Categories of Content of the Baby-directed Maternal Speech*
}

\author{
Ana Karina Santos* (D), Luiz Silva dos Santos (D), \& Vera Silvia Raad Bussab (D) \\ Universidade de São Paulo (USP), São Paulo, SP, Brasil
}

\begin{abstract}
The maternal speech oriented to the baby has been widely studied due to its importance for the child's development. In this article we present a research method and a set of content categories of maternal speech directed to the child. This methodological proposal is based on a survey of 80 dyads of mothers and babies, with and without postpartum depression (PPD). The distribution of frequency of the categories was similar in both groups. There was no statistical difference in the means of categories for mothers with and without PPD, indicating that there is no change in speech style due to maternal depression. In our view, these categories could be applied to study the speech of both healthy mothers and those with postpartum depression.
\end{abstract}

KEYWORDS: maternal speech, codification method, mother-infant interaction, postpartum depression

\section{Método de Codificação e Categorias de Conteúdo do Discurso Materno Dirigido a Bebês}

\begin{abstract}
RESUMO - O discurso materno direcionado ao bebê tem sido amplamente estudado devido a sua importância no desenvolvimento infantil. Neste artigo apresentamos um método de investigação e um conjunto de categorias de conteúdo do discurso materno direcionado à criança. Esta proposta metodológica baseia-se numa pesquisa realizada com 80 díades de mães e bebês, com e sem depressão pós-parto (DPP). A distribuição das frequências das categorias foi semelhante nos dois grupos. Não houve diferença estatística nas médias das categorias para as mães com e sem DPP, indicando que não há mudança no estilo de discurso em função da depressão materna. Consideramos que as categorias podem ser aplicadas no estudo do discurso de mães saudáveis ou com depressão pós-parto.
\end{abstract}

PALAVRAS-CHAVE: discurso materno, método de codificação, interação mãe-bebê, depressão pós-parto

Baby-directed maternal speech, also called motherese, has a universal biological component and shares common characteristics in different languages, such as higher pitches, frequent repetition and prolongation of vowel sound (Papoušek, 2007). It is also characterized by differentiated speech, simpler, infantilized and with an exaggerated intonation that fits the baby's ability to understand and raise the baby's interest on interaction (Fernald, 1985).

When babies are two or three months of age, their interactions with the caregiver become intensively based on verbal practices: mothers usually treat their babies as an active partner during dialogues, in a pattern of dyadic exchanges, making it seems a conversation that takes place between she and the baby (Stern, 1992).

The intensity of a mother talking to her baby seems to indicate the existence of relevant functions in this care system for maintaining interaction and developing essential skills, including language (Dominey \& Dodane, 2004). Conversation and narrative practices aimed at communicating with the baby also bear psychological function of providing grounds for the child to build notions of self, perceiving themselves as individuals through the social relations (Keller, Borke, Lamm, Lohaus, \& Yovsi, 2011). Moreover, they prepare the baby for future learning environments, as it suggests the possibility that

* Supported: FAPESP

**E-mail: anakst@gmail.com

n Submetido: 27/12/2016; Revisado: 24/04/2018; Aceito: 08/09/2018. 
direct communication with the baby meets several purposes, including stimulating cognitive skills and knowledge of norms and expectations of their social environment (Keller, 2007).

Surveys on maternal speech may have different focuses of analysis, including: intonation, recognition of the mother's voice by the baby, the baby's preference for motherese and the content of maternal speech, the subject of this article.

Bornstein, Tal and Rahn (1992) hypothesized that mothers intuitively adjust the content of their speech to the age of the baby. The authors compared the speech of mothers with 5-month and 13-month old babies in four different cultures. Data showed similar variation across cultures for the most frequent type of speech according to the child's age: affectionate speech with 5-month-olds and more informative language with 13-month-olds. The observations made by Pessôa and Seidl-de-Moura (2011) are in line with this hypothesis. A longitudinal analysis of the speech of two mothers and their 13-month to 24-month old infants revealed that maternal speech is based on interactions aimed at drawing the child's attention to the social context and surroundings. This type of speech decreases from week 62 onwards when verbal interactions based on more symbolic content start emerging.

The survey by Keller et al. (2011) suggests that the content of maternal speeches mirrors trends of the socialization path of each culture. The study of babies of German and Nso families, a rural community in Cameroon, indicated that German mothers use a style of speech marked by statements that emphasize the child's autonomy and cognitive abilities, while Nso mothers use a discursive style that focuses on affective bonds and social rules. The study by Mendes and Seidl-de-Moura (2013), conducted in Rio de Janeiro, used the categories of the study by Keller et al. (2011). The authors followed two mother-baby dyads from birth to six months of age. The results showed that maternal speech also carried expressions focused on the child's socio-affective environment and content that emphasized the development of their autonomy.

It is believed that both how the function of childrendirected maternal speech is affected by the emotional state of the mother. Murray, Kempton, Woolgar and Hooper (1993) comparing the discourse of mothers with and without postpartum depression (PPD) addressed to their babies of two and three months old concluded that the speech of depressed mothers is focused on their own experience, bears high percentage of negative affect, as well as few references to child agency. Their analyses also suggested that when mothers engaged their babies of four months in childcentered conversation practices, they performed better on language-related tasks at 18 months. Herrera, Reissland and Sherpherd (2004) also comparing mothers with and without PPD at six months of age, found that non-depressed mothers were more likely to contribute to emotional exchanges and to transmit or confirm cognitive information regarding their experiences with their children.

Studies suggest that the change in vocalization during mother-infant interactions may be a risk marker for later diagnosis of several infant psychopathologies. Murray, Marwick and Arteche (2010) when further analyzing the same children the same children from the study by Murray et al. (1993) - reported in the previous paragraph - at 13 years of age found an association between the development of affective disorders in these adolescents and the presence of maternal speech characteristics (at 2-3 months) that signaled sadness. The research by Allely et al. (2013) found that low frequencies of maternal vocalization when children were one year old predicted psychiatric diagnosis after seven years of age. Murray et al. (2014) pointed out that lower levels of maternal incentive in discourses directed at their 4-5 year olds predicted higher levels of problems of internalization and anxiety in children.

This paper aims to propose an investigation method and a set of categories related to the content of maternal speech. This method was designed to perform the postdoctoral research of the first author that tried to analyze the speech of mothers, with and without PPD, in order to investigate potential differences in speech content due to maternal depression. The research was funded by FAPESP (proceeding 2012 / 06774-5) as part of the Thematic Project (proceeding 06/59192) "Postpartum depression as a risk factor for infant development: an interdisciplinary study of the factors involved in the genesis of the condition and its consequences". The study was developed at the Institute of Psychology, University of São Paulo (USP). The project monitored mothers and babies treated by the public health system in the Butantã region, São Paulo, from the third trimester of pregnancy to the third year of the child. PPD evaluation was performed using the Edinburgh Postnatal Depression Scale (EDPE) by Cox, Holden and Sagovsky (1987), validated in Brazil by Santos, Martins and Pasquali (1999).

\section{CODIFICATION METHOD OF THE MATERNAL SPEECH}

\section{Ethical Procedures}

This research employed the FAPESP thematic project documents, previously submitted and approved by three ethics committees: Research Ethics Committee of the
Teaching Hospital of the University of São Paulo (CEPHU / USP: 673/06 - SISNEP CAAE: 0051.0.198.000-06); Research Ethics Committee of the Institute of Psychology of the University of São Paulo (Of.0806 / CEPH-04/07/06); and Research Ethics Committee of the Municipal Health 
Secretariat of the Municipality of São Paulo (CEPSMS: CAAE 0123/06). The research assistants contacted the pregnant women in primary care units. After signing the Informed Consent Form, participants were assessed during seven periods of their prenatal and postnatal life: third trimester of pregnancy, 24-48 hours after birth, 4-6, 8, 12, 24 , and 36 months. For the purposes of this study, only data extracted at 4-6 months were analyzed.

Eighty mothers participated in this survey, of which 40 with PPD and 40 without PPD. The mean age was 26.3 years spanning a large age range (16-40 years). From data such as educational level, which in Brazil is strongly associated with income, the fact of being users of the public health system and the place of residence, associated with the interviewers' perception when they went to their homes, we could infer that most of the mothers were low-income persons.

Babies' ages ranged from three to six months, with 49 babies of four to five months, 16 of three to four months, 14 of five to six months and one baby older than six months. This phase is considered the beginning of the primary period of intersubjectivity (up to nine months), ideal for assessing the child's engagement in face-to-face interactions (Trevarthen \& Aitken, 2001). The sample was gender-balanced: 18 boys and 22 girls in each of the mother groups. All babies were considered healthy by the medical staff of the Teaching Hospital of USP.

Researchers of the thematic project at the Behavior Observation Laboratory of the USP Institute of Psychology shot mothers and their babies in a free play situation. To the shooting, the mother was asked to stay face to face with her baby and interact with him as she would do at home. Each dyad was filmed during a single session lasting ten minutes.

The first step of the work was to select the videos with quality sound and image enough for use in the survey. To ensure sequential coding, videos should not engage the mother in activities that did not involve interaction with the baby. We have also considered that the baby should not show any signs of discomfort due to a health condition, sleep etc.

In order to achieve more accurate result, the video analysis was performed using the Interact Mangold 8.0 software, which allows encoding behavioral data through shortcuts programmed to activate the recording of the behavior observed. Extracting video behavioral data through Interact Mangold requires the preparation of a coding worksheet programmed according with the objectives of the study. As our interest was to record the content of maternal speech, we applied an event-based coding system, that is, the spreadsheet model adopted was programmed to record the occurrence of behaviors within fixed time intervals.

The total video time was divided into five-second intervals to enable a more accurate identification of babyoriented maternal speech, which is characterized by shorter and simpler sentences.
All videos were encoded starting at time zero and ending when they were ten minutes. It is imperative that length is the same for all videos to ensure that all dyads are observed at identical times, at the beginning of the interaction, in the middle and by the end. This standardization allows us to identify how mothers formulate their speeches according to variables such as: foster interaction in the first minutes, keep motivation to interact with the baby over time, and show signs of boredom or tiredness by the end of the session.

Depending on the characteristics of motherese that could hamper the clear understanding of what the mother says, each video was watched at least twice so that the speech was understood to the best possible, minimizing the loss for content that was not understood.

The unit of speech analysis adopted was the emission, defined as each segment marked by a noticeable pause or intonation, regardless of being a complete sentence (Pessôa \& Seidl-de-Moura, 2008). Thus, an issue can be reduced to a single word, e.g. "baby!" Or "where?" This emission criterion as a unit of analysis fits the peculiarities of motherese.

The content of maternal speech was classified into categories. The occurrence of the categories was recorded in each interval.

\section{Categories of Maternal Speech Content}

The categories of analysis proposed herein are based on the following works: 1 . Keller (2007) on maternal speech in different cultural contexts. 2. Murray et al. (1993) on maternal speech in the context of postpartum depression. 3 . Mendes and Seidl-de-Moura (2013) about maternal speech in the first six months of the baby's life. We clustered these references to create a set of categories. Table 1 presents the categories and their respective definitions and functions.

In order to test if the categories covered all possible speech content classifications, the speeches of ten mothers (randomly chosen in each group) were transcribed. Speeches were classified according to an initial set of categories. It was observed that some categories were quite infrequent. Initially these lines were grouped according to shared elements. Categories with related content and that occurred less frequently were aggregated, and then a new classification was created.

To test whether the categories covered the content of maternal speech, we also recorded the speeches that did not fit into any of the categories and calculated the percentage of these speeches, which reached values lower than $10 \%$ of the total frequency of all categories, which is considered acceptable for analysis purposes.

The categories were not considered unique per unit of speech, a sentence could be classified in more than one category. For example, in the statement "Are you sleepy, my sweetie?" we identify two categories: affirmation of 
Table 1

Definition of the categories of the material speech's content, references, examples and functions

\begin{tabular}{|c|c|c|c|}
\hline Category & Definition & Example & Function \\
\hline Agency & $\begin{array}{l}\text { Mother refers to the baby like as having, or } \\
\text { starting intentions, emotions, preferences or } \\
\text { decisions. }\end{array}$ & $\begin{array}{l}\text { "Are you angry at mom?" } \\
\text { "Are you talking?" }\end{array}$ & $\begin{array}{l}\text { The mother interprets that the baby can } \\
\text { exercise skills that are yet to be developed. }\end{array}$ \\
\hline $\begin{array}{l}\text { Affirmation } \\
\text { of needs }\end{array}$ & $\begin{array}{l}\text { The mother refers to the baby's individual } \\
\text { needs or satisfaction. }\end{array}$ & $\begin{array}{l}\text { "Do you want to suck?" } \\
\text { "Mom takes you in her arms." }\end{array}$ & $\begin{array}{l}\text { Show the baby that the mother understands his } \\
\text { needs and how to meet them. }\end{array}$ \\
\hline $\begin{array}{l}\text { Self- } \\
\text { reference }\end{array}$ & $\begin{array}{l}\text { The mother refers to herself as who is } \\
\text { speaking, emphasizing how she feels and her } \\
\text { own experience. }\end{array}$ & "Mom is so tired." & $\begin{array}{l}\text { Express how she feels physically and } \\
\text { emotionally, including about care to the baby. }\end{array}$ \\
\hline Assessment & $\begin{array}{l}\text { The mother praises the baby, parts of his body } \\
\text { or his behavior. }\end{array}$ & $\begin{array}{l}\text { "What a pretty boy!" } \\
\text { "What a strong baby, picked } \\
\text { the ball!". }\end{array}$ & $\begin{array}{l}\text { Show the baby his qualities and praise him } \\
\text { when he expresses some behaviors. }\end{array}$ \\
\hline $\begin{array}{l}\text { Regulation } \\
\text { of behavior }\end{array}$ & $\begin{array}{l}\text { Control the child's behavior referring to how } \\
\text { it should behave. Includes, social rules or } \\
\text { reference to an authority. }\end{array}$ & $\begin{array}{l}\text { "Don't take the toy into your } \\
\text { mouth!" "Dad told you not to } \\
\text { do that you may fall!" }\end{array}$ & $\begin{array}{l}\text { Drives the child's Behavior, showing that there } \\
\text { are limits and rules to be followed. }\end{array}$ \\
\hline Co-agency & $\begin{array}{l}\text { The mother refers to the child as acting } \\
\text { jointly with someone (typically the mother). }\end{array}$ & "Let's go to a walk!" & $\begin{array}{l}\text { Set in the baby a sense of social } \\
\text { interdependence. }\end{array}$ \\
\hline $\begin{array}{l}\text { Drive } \\
\text { attention }\end{array}$ & $\begin{array}{l}\text { Drive the baby's attention to her or to } \\
\text { elements of the context. }\end{array}$ & $\begin{array}{l}\text { "Look at mom!" } \\
\text { "See what a beautiful rattle!" }\end{array}$ & $\begin{array}{l}\text { Engage the child in the interaction and keep the } \\
\text { child's attention on the mother and the situation } \\
\text { that surrounds them. }\end{array}$ \\
\hline $\begin{array}{l}\text { Social } \\
\text { context }\end{array}$ & $\begin{array}{l}\text { The mother talks about the baby's social } \\
\text { context or about other persons }\end{array}$ & "It's dad, pretty baby!" & $\begin{array}{l}\text { Inform the baby about its socio-affective } \\
\text { environment. }\end{array}$ \\
\hline Treatment & $\begin{array}{l}\text { Refer to the child in a loving or functional } \\
\text { way. Includes calling by nicknames. }\end{array}$ & $\begin{array}{l}\text { "My love!" } \\
\text { "Hi, son!" }\end{array}$ & $\begin{array}{l}\text { Show the baby's individual importance to the } \\
\text { mother. }\end{array}$ \\
\hline $\begin{array}{l}\text { Give voice } \\
\text { to the baby }\end{array}$ & $\begin{array}{l}\text { Mother talks on behalf of the baby, in the first } \\
\text { singular person to refer to internal states and } \\
\text { behaviors of the baby. }\end{array}$ & $\begin{array}{l}\text { "I'm asleep, mom!" } \\
\text { "I didn't like the toy" }\end{array}$ & $\begin{array}{l}\text { Shows that the mother can interpret states, } \\
\text { emotions and feelings of the baby. }\end{array}$ \\
\hline $\begin{array}{l}\text { Other } \\
\text { speeches }\end{array}$ & Speeches that do not fit into any category. & - & - \\
\hline $\begin{array}{l}\text { Inaudible } \\
\text { sounds }\end{array}$ & $\begin{array}{l}\text { Speeches that could not be heard or } \\
\text { unintelligible speeches }\end{array}$ & - & - \\
\hline
\end{tabular}

Table 2

Agreement indicators in decreasing order

\begin{tabular}{lc}
\hline Mother's speech categories & Kappa Index \\
\hline Co-agency & 0.88 \\
Affirmation of need & 0.77 \\
Treatment & 0.77 \\
Give voice to the baby & 0.76 \\
Drive attention & 0.75 \\
Regulation of behavior & 0.71 \\
Agency & 0.68 \\
Self-reference & 0.67 \\
Assessment & 0.63 \\
Social context & 0.62 \\
\hline
\end{tabular}

needs ("are you sleepy...") and treatment ("my sweetie"). Repetitions were counted normally, so if the mother said "you are beautiful" twice, we counted twice the "assessment" category.
Two independent researchers coded $20 \%$ of the total videos for the purpose of verifying the agreement rate. Coding was blind, i.e., not knowing of maternal status in relation to PPD. Table 2 presents the reliability index of the categories measured by the Cohen's Kappa statistical test. Agreement rates ranged from substantial to excellent.

Data were carried from Interact to the Statistical Package for Social Sciences (SPSS) statistical analysis program. The datasheet was reduced by summing the occurrences of the categories by intervals. Each video had 1205 -second intervals, totaling 9600 sample intervals. Of this total, 259 intervals were classified as inaudible and were not coded (because we did not understand the mother's speech, due to video technical problems or due to noise in the interaction environment), so we had 9341 coded intervals, with an average of 116,7 breaks per mother. To correct for differences in interaction durations, category frequencies were calculated proportionally to the number of audible intervals. Thus, the total number of lines per category was divided by the number of intervals coded. 


\section{RESULTS}

The total frequency of speeches was 12,468 issuances in 778.4 minutes of interaction, with an average of 15.5 issuances a minute $(\mathrm{SD}=5.9)$. The total number of speeches for mothers without PPD was 6,514, with an average of 16.2 speeches a minute $(\mathrm{SD}=6.1)$. Depressed mothers reported lower figures, with a total of 5,954 lines and an average of 14.8 lines a minute $(\mathrm{SD}=4.9)$. However, the difference between the means of the two groups was not statistically significant.

Regarding categories, results were also similar to the groups. As shown in Table 3, statements indicating agency corresponded to $32.8 \%$ (16.9) of the speeches for mothers without PPD and 31.4\% (14.8) for mothers with PPD. "Direct attention" reported the second highest frequency, being $23.3 \%$ (11.9) of speeches by mothers without depression and $24.2 \%$ (11.3) of speeches by depressed mothers. "Treatment" was the third most frequent category, corresponding to $16.3 \%$ (8.4) and $18.6 \%$ (8.7) for the group without and with PPD, respectively. The following two categories had the values of - following the order of

presentation by mothers without and with PPD: giving voice to the baby $-6.8 \%(3.5)$ and $7.2 \%$ (3.3) and behavior regulation $-5.5 \%(2.8)$ and $5.1 \%(2.4)$. The next five categories each individually corresponded to less than $10 \%$ of the total speech, with approximate values between groups. There was also no statistical difference between the groups in the means of the categories.

These results are in line with the hypothesis of Bornstein et al. (1992) that mothers intuitively adjust the content of their speech according to the age of the baby. Agency, as the most frequent category, plays the role of giving the baby skills that are yet to be developed. Thus, the mother seems to stimulate cognitive skills in the child. This data is also in line with the study by Murray et al. (1993), in which agency also appears as the speech most produced by mothers.

"Directing attention" appears as the second most frequent type of speech, what can be expected at this stage of development where interaction is mainly face-to-face, demanding a type of communication in which the child's attention is on the mother. The treatment category especially depicts an affectionate way of approaching the baby, is a predominantly affectionate speech and, as suggested by Keller et al. (2011) is related to cultural environments in which the goals of parental socialization emphasize interdependence (Keller, 2007). The high percentage of speech related to agency (indicator of autonomy) and treatment is in line with the idea presented by Keller et al. (2011) that motherese is permeated by contents that reflect the socialization goals of each culture. The Brazilian research on parental socialization goals shows that in Brazil there is a tendency to value interdependent

goals as much as those that emphasize child autonomy (Seidl-de-Moura et al., 2017; Vieira et al., 2010).

"Giving the baby a voice" has as a special reference the internal states of the baby construed by the mother and spoken by her like as if she were the child. This category expresses a mother's ability to interpret behaviors and put herself in the baby's shoes in a subjective effort to establish an empathic connection with the child. As such, lower frequency of this type of speech was expected for depressed mothers, which occurred in a very subtle but not significant way. Results related to behavior regulation should be viewed with caution, since their definition assumes the use of imperatives, which throughout development could mean an attempt by mothers to impress organization on their children's conduct. On the other hand, it may also indicate

Table 3

Proportional frequency of each category by group of mothers

\begin{tabular}{|c|c|c|c|c|c|c|}
\hline \multirow{2}{*}{ Category } & \multicolumn{2}{|c|}{$\begin{array}{c}\text { No DPP } \\
\mathrm{n}=40\end{array}$} & \multicolumn{2}{|c|}{$\begin{array}{c}\text { With DPP } \\
\mathrm{n}=40\end{array}$} & \multicolumn{2}{|c|}{$\begin{array}{l}\text { Total } \\
\mathrm{N}=80\end{array}$} \\
\hline & $\%$ & $\mathrm{f}$ & $\%$ & $\mathrm{f}$ & $\%$ & $\mathrm{f}$ \\
\hline Agency & 32.8 & 16.9 & 31.4 & 14.8 & 32.2 & 31.7 \\
\hline Drive attention & 23.3 & 11.9 & 24.2 & 11.3 & 23.7 & 23.2 \\
\hline Treatment & 16.3 & 8.4 & 18.6 & 8.7 & 17.4 & 17.1 \\
\hline Give voice to the baby & 6.8 & 3.5 & 7.2 & 3.3 & 6.9 & 6.8 \\
\hline Regulation of behavior & 5.5 & 2.8 & 5.1 & 2.4 & 5.3 & 5.2 \\
\hline Social context & 5.0 & 2.5 & 4.3 & 2.1 & 4.7 & 4.6 \\
\hline Assessment & 4.7 & 2.4 & 4.2 & 2.0 & 4.5 & 4.4 \\
\hline Affirmation of need & 2.2 & 1.2 & 1.9 & 0.9 & 2.1 & 2.1 \\
\hline Self-reference & 1.8 & 0.9 & 1.8 & 0.8 & 1.7 & 1.7 \\
\hline Co-agency & 1.6 & 0.8 & 1.3 & 0.6 & 1.5 & 1.4 \\
\hline Total & 100.0 & 51.3 & 100.0 & 46.9 & 100.0 & 98.2 \\
\hline
\end{tabular}


an excessive attempt to control the baby's behavior. Thus, we suggest future studies where the use of this category would point out if the mother guides the child's behavior or delimits it through prohibitions.

These results are in line with the studies by Herrera et al. (2004) and Murray et al. (1993) showing a negative modification of the functional content of maternal speech as a function of the PPD. Here, the frequencies of the categories point to very similar speech between the groups. It is noteworthy that although there is no significant difference, frequencies are still higher for non-depressed mothers in all categories, except for the treatment category. This category expresses affection, but we believe that the slightly higher frequency for mothers without PPD regards the fact that they call their children more to attract their attention, perhaps more dispersed as a result of some interactional disruption due to maternal depression.

The results indicate, therefore, that the speech content does not change due to the presence of maternal depression. Thus, we consider that these categories can be applied in the study of the speech of both healthy mothers and mothers with postpartum depression.

\section{FINAL REMARKS}

A difficulty we faced to conduct this study was to understand the content of the mothers' speech. Babydirected maternal speech in the pre-verbal phase, as the focus of this research, is contextualized in an already established mother-child relationship that gains its own contours according to the history of this relationship, the characteristics of the mother, the baby and the child and of the context of nurturing. Persistence to understand the content of speech translates into the need to listening the whole speech several times to better understand its speech and specific contents, taking to the lowest level possible the number of misunderstood sentences. For these reasons, the work of measuring reliability is a very important step and may last more than the expected.
We suggest that during the coding process notes are made about variables present at the moment of interaction that could influence data. These may be related to the baby (crying, discomfort), the mother (being distracted or bored), the environment (outside noise) or the material used in the filming (misplaced camera). In addition, the researcher's impressions of the interaction should be noted. This could ensure more accurate analysis, with qualitative purposes, of mothers whose speech deviates from the general pattern of the sample.

Finally, we emphasize that this proposal applies to a typical mother-baby interaction situation. In the case of an atypical situation, we believe the coding method could be maintained, but the application of the category system should be evaluated.

\section{REFERENCES}

Allely, C. S., Purves, D., McConnachie, A., Marwick, H., Johnson, P., Doolin, O., ... Wilson, P. (2013). Parent-infant vocalizations at 12 months predict psychopathology at 7 years. Research in Developmental Disabilities, 34, 985-993. doi: 10.1016/j. ridd.2012.11.024

Bornstein, M., Tal, J., \& Rahn, C. (1992). Functional analysis of the contents of maternal speech to infants of 5 and 13 months in four cultures: Argentina, France, Japan, and United States. Developmental Psychology, 28(4), 593-603. doi: 10.1037/0012-1649.28.4.593.

Cox, J. L., Holden, J. M., \& Sagovsky, R. (1987). Detection of postnatal depression: Development of the 10 item Edinburgh Postnatal Depression Scale. British Journal of Psychiatry, 150(6), 782- 786. doi: 10.1192/bjp.150.6.782

Dominey, P. F., \& Dodane, C. (2004). Indeterminacy in language acquisition: The role of child direct speech and joint attention. Journal of Neurolinguistics, 17, 121-145. doi: 10.1016/S09116044(03)00056-3

Fernald, A. (1985). Four-month-old infants prefer to listen to motherese. Infant Behavior and Development, 8, 181-195. doi: 10.1016/S0163-6383(85)80005-9

Herrera, E., Reissland, N., \& Sherpherd, J. (2004). Maternal touch and maternal child-directed speech: effects of depressed mood in the postnatal period. Journal of Affective Disorders, 81(1), 29-39. doi: 10.1016/j.jad.2003.07.001

Keller, H. (2007). Cultures of infancy. Mahwah, NJ: Lawrence Erlbaum Associates.

Keller, H., Borke, J., Lamm, B., Lohaus, A., \& Yovsi, R. D. (2011). Developing patterns of parenting in two cultural communities. International Journal of Behavioral Development, 35(3), 233245. doi: 10.1177/0165025410380652

Mendes, D. M. L. F., \& Seidl-de-Moura, M. L. (2013). O envelope narrativo e o desenvolvimento do self: Um estudo longitudinal com mães e bebês nos seis primeiros meses de vida. [The narrative envelope and self-development: A longitudinal study with mothers and babies in the first six months of life]. Interação em Psicologia, 17(1), 37-46. doi: 10.5380/psi. v17i1.20108

Murray, L., Kempton, C., Woolgar, M., \& Hooper, R. (1993). Depressed mothers' speech to their infants and its relation to infant gender and cognitive development. Journal of Child Psychology and Psychiatry, 34(7), 1083-101. doi:10.1111/j.1469 7610.1993.tb01775.x

Murray, L., Marwick, H., \& Arteche, A. (2010). Sadness in mothers' 'baby-talk' predicts affective disorder in adolescent offspring. 
Infant Behavior and Development, 33(3): 361-364. doi: 10.1016/j.infbeh.2010.03.009.

Murray, L., Pella, J. E., De Pascalis, L., Arteche, A., Pass, L., Percy, ..., Cooper, P. J. (2014). Socially anxious mothers' narratives to their children and their relation to child representations and adjustment. Development and Psychopathology, 26, 1531-1546. doi:10.1017/S0954579414001187

Papoušek, M. (2007). Communication in early infancy: An arena of intersubjective learning. Infant Behavior \& Development, 30(2), 258-266. doi: 10.1016/j.infbeh.2007.02.003

Pessôa, L. F., \& Seidl-de-Moura, M. L. (2008). Características pragmáticas da fala materna em díades mãe-bebê (aos cinco e vinte meses). Arquivos Brasileiros de Psicologia, 60 (1), 82-95.

Pessôa, L. F., \& Seidl-de-Moura, M. L. (2011). Fala materna dirigida à criança em cenários comunicativos específicos: Um estudo longitudinal. [Child-directed maternal speech in specific communicative settings: A longitudinal study]. Psicologia: Teoria e Pesquisa, 27(4), 439-447. doi: 10.1590/ S0102-37722011000400007.

Santos, M. F. S., Martins, F. C., \& Pasquali, L. (1999). Escalas de autoavaliação de depressão pós-parto: Estudo no Brasil.
[Postpartum depression self-assessment scales: A study in Brazil]. Revista de Psiquiatria Clínica, 26(2), 32-40.

Seidl-de-Moura, M. L., Ramos, D. O., Pessôa, L. F., Carvalho, R. V. C., Victor, T.A. S., \& Mendes, M.L. F. (2017). Autonomia-relacionada como tendência do desenvolvimento do self: Novas evidências em um contexto brasileiro. [Autonomy-related as self development trend: New evidence in a Brazilian context]. Psicologia: Teoria e Pesquisa, 33, 1-9. doi: 10.1590/0102.3772e3333.

Stern, D. N. (1992). The 'pre-narrative envelope': An alternative view of 'unconscious phantasy'. Bulletin of the Anna Freud Center, 15, 291-318.

Trevarthen, C., \& Aitken, K. J. (2001). Infant intersujectivity: research, theory, and clinical applications. Journal of Child Psychology and Psychiatry, 42(1), 3-48. doi: 10.1111/14697610.00701

Vieira, M. L., Seidl-de-Moura, M. L., Macarini, S. M., Martins, G. D. F., Lordelo, E. D. R., Tokumaru, R. S., \& Oliva, A. D. (2010). Autonomy and interdependence: Beliefs of Brazilian mothers from state capitals and small towns. The Spanish Journal of Psychology, 13(2), 818-826. doi: 10.1017/ S113874160000247X 